\title{
Diarreia em bezerros no sul do Rio Grande do Sul em um período de 34 anos*
}

\section{Diarrhea in calves in Southern Rio Grande do Sul in a period of $\mathbf{3 4}$ years}

\author{
Sergio Farias Vargas Junior, ${ }^{* *}$ Daniel Machado Alves, ${ }^{* *}$ Rosimeri Zamboni, ${ }^{* *}$ Clairton Marcolongo Pereira, ${ }^{* * *}$ \\ Ana Lucia Schild, ${ }^{* *}$ Eliza Simone Viegas Sallis**
}

\begin{abstract}
Resumo
O objetivo deste trabalho foi descrever os dados de um estudo retrospectivo nos registros de 34 anos atividade de um laboratório de diagnóstico sobre as causas de diarreia em bezerros na região sul do Rio Grande do Sul. Foram revisados os protocolos de necropsia e materiais desta espécie encaminhados ao Laboratório Regional de Diagnóstico da Faculdade de Veterinária da Universidade Federal de Pelotas. Foram diagnosticados 94 casos de bezerros com diarreia, destes, 44,7\% foram de causas parasitárias e $34,0 \%$ de causas bacterianas. Diarreia de causa parasitária foi a mais importante na região sul do Rio Grande do Sul e afetou bezerros de três a 12 meses de idade. A ocorrência de diarreia em animais mesmo lactentes pode estar associada a fatores ambientais e a forma de manejo no qual esses animais são mantidos. As enfermidades bacterianas foram, também, importantes causas de diarreia em bezerros de até três meses de idade na região.
\end{abstract}

Palavras-chave: doença, Escherichia coli, nematódeos gastrintestinais, rebanho bovinos.

\begin{abstract}
The objective of this work was to describe the data from a retrospective study in the records of 34 years of activity in a diagnostic laboratory on the diarrhea causes of in calves in the southern region of Rio Grande do Sul. All necropsy protocols and materials received in the Regional Diagnostic Laboratory of the Veterinary School of the Federal University of Pelotas were reviewed. Ninetyfour cases of calves with diarrhea were diagnosed, of these, $44.7 \%$ were caused by parasitic infections and $34.0 \%$ by bacterial infections. Parasites as cause of diarrhea was the most important diagnostic in southern Rio Grande do Sul and affected calves from three to 12 months of age. The occurrence of diarrhea in animals even infants may be associated with environmental factors and the form of management that these animals are kept. Bacterial diseases are also important causes of diarrhea in calves up to three months of age in the region.
\end{abstract}

Keywords: attle herd, disease, Escherichia coli, gastrointestinal nematodes

\section{Introdução}

A diarreia em bezerros é uma das causas mais comuns e importantes de perdas econômicas na cadeia produtiva de bovinos, pois acarreta perdas relacionadas com gastos com tratamento, queda dos índices de produtividade e morte dos animais acometidos (Langoni et al. 2004, Cho et al. 2013). É considerada uma síndrome de origem multifatorial, relacionada a agentes infecciosos e fatores não infecciosos, como o manejo e o ambiente (Benesi 1999).

No Brasil há estudos que comprovam a importância das diarreias como causa de mortalidade neonatal em bezerros leiteiros (Langoni et al. 2004). Em bovinos de corte são escassos os estudos que descrevem a casuística de diarreia no país, apesar dos prejuízos econômicos causados pelo distúrbio (Oliveira Filho et al. 2007). Em um estudo realizado no sul do Rio Grande do Sul, num período de 11 anos, foi observado que as principais causas de mortalidade em bezerros estavam relacionadas a problemas respiratórios e entéricos. Das doenças entéricas observadas, 60,9\% cursavam com diarreia (Assis-Brasil et al. 2013).

O objetivo deste trabalho foi descrever os dados de um estudo retrospectivo nos registros de 34 anos atividade de um laboratório de diagnóstico e determinar as principais causas de diarreia em bezerros na região sul do Rio Grande do Sul.

\section{Material e métodos}

Foram revisados os protocolos de necropsia e/ou materiais de bovinos recebidos no Laboratório Regional de Diagnóstico da Faculdade de Veterinária da Universidade Federal de Pelotas (LRD/UFPel) entre janeiro de 1980 e dezembro de 2014. Desses protocolos foram extraídas informações referentes ao número total de bezerros e o número total de bezerros com histórico clínico de diarreia. Foram coletados, também, dados referentes à idade, sexo, raça e o material enviado para

\footnotetext{
${ }^{*}$ Recebido em 25 de novembro de 2020 e aceito em 4 de janeiro de 2021.

**Universidade Federal de Pelotas (UFPel), Faculdade de Veterinária, Departamento de Patologia Animal, Capão do Leão, RS, Brasil.

***UniRitter, Faculdade de Veterinária , Porto Alegre, RS, Brasil.

Autor para correspondência: juniorfvargas@hotmail.com
} 
diagnóstico, época do ano, bem como a etiologia da diarreia. Os diagnósticos foram distribuídos por faixa etária em bezerros de um dia a três meses, bezerros entre quatro-sete meses e bezerros entre oito-12 meses de idade, e foram agrupados de acordo com a etiologia e a faixa etária. Nos casos em que apenas o diagnóstico morfológico era mencionado no protocolo de necropsia e/ou materiais recebidos, os diagnósticos foram agrupados em diagnósticos indeterminados. Nos protocolos em que o diagnóstico não foi estabelecido os casos foram considerados inconclusivos.

\section{Resultados e discussão}

De um total de 6.222 necropsias e/ou materiais de bovinos recebidos no LRD/UFPel entre janeiro de 1980 e dezembro de 2014, $1.139(18,3 \%)$ corresponderam a bezerros, destes, 216 (19\%) tinham patologias do trato gastrintestinal e $94(43,5 \%)$ eram de bovinos de até 12 meses de idade com quadro clínico de diarreia.

Dos materiais encaminhados para diagnóstico, 54 eram provenientes de cadáveres, 27 de amostras de fezes e 13 eram fragmentos de intestino. Destes, 42 casos corresponderam a doenças parasitárias, 32 casos a doenças bacterianas, 17 casos a diagnósticos indeterminados, um caso foi presuntivo de rotavírus e dois casos foram inconclusivos.

Dos diagnósticos observados, as doenças bacterianas tiveram 28 casos de infecção por Escherichia coli e quatro casos de infecção por Salmonella spp. Os nematódeos gastrintestinais tiveram 37 casos, nos quais seis eram infecção por Haemonchus spp., quatro eram de Ostertagia spp., três de Moniezia spp., três da família Strongyloidea e um caso de Cooperia spp. Em nove casos foi observado infecção mista por mais de um nematódeo gastrintestinal e em 11 casos não foi mencionado o parasita envolvido na infecção. Com relação à infecção por protozoários, eimeriose foi diagnosticada em quatro casos e em um caso criptosporidiose. Em 17 casos os diagnósticos foram indeterminados.

Dos 94 casos de bezerros com diarreia, 46 animais tinham idade entre um dia e três meses; 17 casos tinham entre quatro e sete meses; 30 casos tinham entre oito e 12 meses e em um caso a idade não estava especificada no protocolo.

Com relação à raça dos bezerros afetados, 48 eram das raças leiteiras (28 da raça Holandês e 20 da raça Jersey) e 24 eram de raças de corte (oito da raça Hereford, sete da raça Aberdeen, seis da raça Charolês e três da raça Devon). Em 17 casos os animais não tinham raça definida e em cinco casos a raça não constava no protocolo de necropsia.

Os resultados do presente estudo demonstraram que das causas de diarreia que afetaram bezerros até um ano de idade, a diarreia parasitária foi à causa mais importante na região sul do Rio Grande do Sul. Parasitoses por nematódeos gastrintestinais em bezerros são as principais causas de enfermidades do trato digestivo a partir dos seis meses de idade, tendo em vista que bovinos são mais suscetíveis a parasitoses a partir do desmame, que é realizado frequentemente nesta faixa etária (Assis-Brasil et al. 2013). Por outro lado, nesse estudo as enfermidades causadas por parasitas gastrintestinais ocorreram em animais com idades variando de três a 12 meses, o que sugere a susceptibilidade desses animais às infecções por esses agentes.
Provavelmente a contaminação do ambiente foi um dos fatores que contribuiu para o aumento da casuística das parasitoses em bezerros com menos de seis meses de idade neste estudo.

Não foi observada relação entre as estações do ano e os casos de diarreia por parasitose. Fatores ambientais como temperatura, precipitação pluviométrica, solo, tipo e manejo de pastagem podem influenciar na maior prevalência das infecções por nematódeos gastrintestinais (Ruas e Berne 2007). Provavelmente esses fatores podem, também, ter certa influência no desenvolvimento das outras causas de diarreia observada neste trabalho. Entretanto, não foi, também, observado relação das estações do ano com os demais agentes.

Eimeriose ocorreu em 4,3\% dos casos de diarreia em bezerros nesse estudo. A enfermidade geralmente está associada à ingestão de água e alimentos contaminados com o coccidio. Condições precárias de higiene, a alta densidade de animais e umidade excessiva favorecem ao aparecimento da doença (Radostits et al. 2007). Os casos aqui relatados podem ter ocorrido devido ao manejo utilizado nas propriedades, nas quais geralmente utilizam o mesmo ambiente para cria dos bezerros por várias gerações. Fatores como vacinação das vacas, ingestão de colostro em quantidade e qualidade adequados, sanidade geral dos animais também podem ter interferido nestes casos, entretanto, tais fatores não estavam descritos nos registros.

Diarreia por Criptosporidium spp. foi observado em um surto, no qual $8,7 \%$ dos animais adoeceram e $4 \%$ morreram. Esta enfermidade é considerada uma importante causa de diarreia em bezerros, geralmente associada a outros agentes (Radostits et al. 2007). Nesse surto não foi observado associação do Criptosporidum spp com outros enteropatógenos. Tem sido mencionado que este agente pode ser causa primária de diarreia em bezerros (De Graff et al. 1999).

Com relação às enfermidades causadas por bactérias, a infecção por Escherichia coli foi a doença mais frequentemente diagnosticada, com $29,8 \%$ dos casos. Em outros estudos, a diarreia em bezerros por $E$. coli foi a mais frequente, principalmente nas primeiras semanas de vida, sendo uma das principais causas de morbidade e mortalidade nessa espécie (Langoni et al. 2004). Infecções por esta bactéria ocorrem principalmente em bezerros jovens, com até três meses de idade devido a imaturidade imunológica, tornando-os mais suscetíveis à ação de cepas patogênicas (Magalhães et al. 1991), como foi observado nesse estudo, no qual bezerros de até três meses de idade foram os mais acometidos.

Infecção por Salmonella spp. foi a segunda causa bacteriana mais frequente de diarreia em bezerros com 4,3\% dos casos. Infecções por Salmonella spp. ocorrem por contaminação de alimentos e fômites e geralmente acometem bezerros com mais de um mês de idade, podendo ocorrer, também, em animais mais jovens nas formas septicêmica ou entérica (Benesi 1999). No presente trabalho, os animais infectados tinham idade variando de sete dias a três meses e apenas a forma entérica foi observada. No Brasil a ocorrência de salmonelose em bezerros como causa de diarreia é pouco descrita (Schuch 2007).

No presente estudo, a infecção por rotavírus foi diagnosticada presuntivamente em um caso e por coronavírus não foi observada. Provavelmente, isso pode ser em consequência do material encaminhado para o laboratório e/ou das técnicas 
de detecção utilizadas. Entretanto, esses agentes podem estar associados às infecções bacterianas e parasitárias observadas nesse estudo. Infecções mistas por esses vírus têm sido mencionadas como causa de diarreias em bezerros (Millemann 2009). Em um estudo de diarreia em bezerros nelore no Brasil, rotavírus foi diagnosticado em $11 \%$ dos casos, causando diarreia em associação a outros agentes ou isoladamente (Oliveira Filho et al. 2007).

Com relação às raças de bezerros com diarreia, o maior número de casos foi observado nas raças leiteiras do que nas raças de corte. Isto, possivelmente deve-se ao sistema de criação adotado nas propriedades leiteiras da região e a contaminação do ambiente em que esses animais são mantidos até o desaleitamento.

No presente estudo a taxa de morbidade variou de 0,6 a $72,2 \%$ e a mortalidade de 0,2 a $60 \%$. Em outro estudo sobre as causas de diarreia em bezerros de leite foram observadas taxas de

\section{Referências}

ASSIS-BRASIL, N.D; MARCOLONGO-PEREIRA, C; HINNAH, F.L; LADEIRA, S.R.L; SALLIS, E.S.V; GRECCO, F.B; SCHILD, A.L. Enfermidades diagnosticadas em bezerros na região sul do RS. Pesquisa Veterinária Brasileira. v.33, p. 423 - 430, 2013.

BENESI, F.J. Síndrome diarreia dos bezerros. Revista CRMV-ES. v.2, n.3, p. $10-13,1999$.

CHO, Y.I; HAN, J.I; WANG, C; COOPER, V; SCHWARTZ, K; ENGELKEN, T; YOON, K.J. Case-control study of microbiological etiology associated with calf diarrhea. Veterinary Microbiology. v.166, p.375 - 385, 2013.

DE GRAFF, D.C; VANOPDENBOSCH, E; ORTEGA-MORA, L.M; ABBASSI H; PEETERS, J.E. A review of the importance of cryptosporidiosis in farm animals. International Journal for Parasitology . v.29, p.1269 - 1287, 1999.

LANGONI, H; LINHARES, A.C; AVILA, F.A; SILVA, A.V; ELIAS, A.O. Contribuition to the study of diarrhea etiology in neonate dairy calves in SP state, Brazil. Brazilian Journal of Veterinary Research and Animal Science. v.41, p.313 - 319, 2004.

MAGALHÃES, H; FREITAS, M.A; GONÇALVES, W.M. Ocorrência, aspectos bacteriológicos e histopatológicos da colibacilose de bezerros. Pesquisa Agropecuária Brasileira. v.29, p.555-564, 1991. morbidade de até $100 \%$ e de mortalidade de $50 \%$ (Langoni et al. 2004). As altas taxas de morbidade e mortalidade observadas no presente estudo demonstram a importância econômica da diarreia para a região sul do Rio Grande do Sul. As perdas não estão relacionadas apenas as mortes dos animais, mas também, aos gastos com tratamento, retardo no desenvolvimento, atraso na puberdade e maior susseptibilidade a outras doenças, dentre outras.

Com base nos resultados do presente estudo pode-se concluir que a diarreia de causa parasitária é a mais importante na região sul do Rio Grande do Sul e que a sua ocorrência em animais mesmo lactentes pode estar associada a fatores ambientais e a forma de manejo no qual esses animais são mantidos. As enfermidades bacterianas foram, também, importantes causas de diarreia em bezerros de até três meses de idade na região. Deve-se ressaltar a importância da realização do diagnóstico a fim de se adotar medidas preventivas para minimizar os prejuízos econômicos causados pela diarreia em bezerros.

MILLEMANN, Y. Diagnosisof neonatal calf diarrhea. Revue de Médecine Vétérinaire. v.160, p.404 - 409, 2009.

OLIVEIRA FILHO, J.P; SILVA, D.P.G; PACHECO, M.D; MASCARINI, L.M; RIBEIRO, M.G; ALFIERI, A.A; ALFIERI, A.F; STIPP, D.T; BARROS, B.J.P; BORGES, A.S. Diarreia em bezerros da raça Nelore criados extensivamente: estudo clínico e etiológico. Pesquisa Veterinária Brasileira. v.27, p.419 - 424, 2007.

RADOSTITS, O.M; GAY, C.C; BLOOD, D.C; HINCHCLIFF, K.W. Veterinary Medice: A textbook of the diseases of cattle, horses, sheep, pigs and goats. 10th ed. Philadelphia: Elsevier. 2007. $2156 p$.

RUAS, J.L; BERNE, M.E.A. Parasitoses por nematódeos gastrintestinais em bovinos e ovinos. In: RIET-CORREA, F; SCHILD, A.L; LEMOS, R.A.A; BORGES, J.R.J. Doenças de Ruminantes e Equideos. Vol.1.3 ${ }^{\mathrm{a}}$ ed. Pallotti, Santa Maria, 2007, p.584-604.

SCHUCH, L.F.D. Diarreia em bezerros. In: RIET-CORREA, F; SCHILD, A.L; LEMOS, R.A.A; BORGES, J.R.J. Doenças de Ruminantes e Equideos. Vol.1. $3^{\mathrm{a}}$ ed. Pallotti, Santa Maria, 2007, p.496-508. 